
INTERNATIONAL BULLETIN OF BACTERIOLOGICAL NOMENCLATURE AND TAXONOMY
Vol. 13, No. $1 \quad$ January 15, 1963

pp. $1-22$

DETAILED MINUTES CONCERNING ACTIONS TAKEN IN THE EMENDATION OF THE INTERNATIONAL CODE OF NOMENCLATURE OF BACTERIA AND VIRUSES DURING THE MEETINGS OF THE JUDICIAL COMMISSION OF THE INTERNATIONAL COMMITTEE ON BACTERIOLOGICAL NOMENCLATURE AT THE VIII INTERNATIONAL MICROBIOLOGICAL CONGRESS IN MONTREAL AUGUST, 1962

\author{
W. A. Clark and H.P.R. Seeliger \\ Joint Permanent Secretaries
}

EMENDATIONS OF GENERAL CONSIDERATIONS

Minute 25. Emendation of General Consideration 2 (page 5 of Code). The Commission approved the emendation of General Consideration 2, lines 9-11, to read as follows:

The rules in general are retroactive; names or forms of nomenclature contrary to a rule (illegitimate names or forms) cannot be maintained. Certain rules authorize appendices and define their scope and authority. The rules of nomenclature do not govern the delimitation of taxa nor determine their interrelationships. They do not limit taxonomic freedom in orderly classification. They primarily assess the correctness of names applied to defined taxa.

\title{
EMENDATIONS OF PRINCIPLES
}

Minute 26. Emendation of Principle 2 (page 9 of Code). The Commission approved the emendation of Principle 2 by the insertion of "are" in line 2 as the third word. The emended Principle 2 reads as follows:

Principle 2. In the absence of a relevant rule, or where the consequences of a rule are doubtful, established custom must be followed. In case of doubt, a resumé in which all pertinent facts are outlined should be submitted to the Judicial Commission for an Opinion.

Minute 27. Emendation of Principle 4 (page 11 of Code). The Commission approved the emendation of Principle 4 to read as follows: 
Principle 4. Scientific names of all taxa are usually taken from Latin or Greek. When taken from any language other than Latin, or formed in an arbitrary manner; they are treated as if they were Latin. Latin terminations should be used so far as possible for new names. The classic Latin rules for the Latinization of Greek and other words of non-Latin origin should be followed.

Minute 28. Emendation of Principle 7 (page 13 of Code). The Commission approved the emendation of Principle 7 as follows:

1. Change paragraph designations $7(b), 7(c)$ and $7(d)$, to $7(\mathrm{c}), 7(\mathrm{~d})$ and $7(\mathrm{e})$, respectively.

2. Insert a new paragraph 7(b) following 7(a) to read:

(b) In some genera (in descending sequence) there are recognized sections, subsections, series and subseries. These taxa are placed between subgenus and species.

Minute 29. Emendation of Principle 11 (page 17 of Code).

The Commission approved the emendation of Principle 11 by substitution of "taxa" for "taxonomic groups (taxa) As emended, Principle 11 reads as follows:

Principle 11. The application of the names of taxa is determined by means of nomenclatural types. A nomenclatural type is that constituent element of a taxon to which the name of the taxon is permanently attached, whether as an accepted name or a synonym.

\section{EMENDATIONS OF RULES AND RECOMMENDATIONS}

Minute 30. Emendation of Rules 1, 2, 3, 4, 5a, 6 and 7, and Recommendation $2 a$. The Commission approved emendation of Rules $1,2,3,4,5 \mathrm{a}, 6,7$ and Recommendation 2a by phrasing the rules in the singular number rather than in the plural.

Rule 1. The name of each taxon above the rank of genus is a substantive or an adjective used as a substantive, of Greek or Latin origin, or a Latinized word, in the feminine gender and in the plural number. 
Rule 2. The name of each taxon above the rank of family is taken preferably from a combination of characters covering the nature of the taxon as closely as possible, or from a single character of outstanding importance.

Recommendation $2 \mathrm{a}$. The name of a new order or of a suborder should preferably be based upon the name of the type genus of a contained family.

Rule 3. The name of a taxon between suborder and genus is formed by the addition of the appropriate suffix to the stem of the name of the type genus.

Rule 4. The name of each taxon between subclass and genus has a suffix to fix its taxonomic rank. The suffix for an order is -ales, for a suborder -ineae, for a family -aceae. for a subfamily -oideae, for a tribe -eae, and for a subtribe -inae.

Rule $5 \mathrm{a}$. The name of a genus or a subgenus is a substantive (or an adjective used as a substantive) in the singular number and written with an initial capital. The name may be taken from any source whatever and may even be composed in an arbitrary manner. It is treated as a Latin substantive.

Rule 6. The name of a species is a binary combination consisting of the name of the genus followed by a single specific epithet. If an epithet consists of two or more words, these must either be united or hyphenated.

NOTEl. A specific epithet consisting of two or more words not joined by hyphens when originally published is not to be rejected, but when used the words are to be hyphenated or joined.

A specific epithet is:

(1) An adjective, which must agree grammatically with the generic name, or

(2) A substantive, in the nominative, in apposition with the generic name, or

(3) A substantive in the genitive.

A specific epithet may be taken from any source whatever and may even be composed arbitrarily. Within the same genus, no two species names may bear the same specific epithet. 
NOTE2. The term "epithet" as used here implies a single descriptive phrase consisting of two or more words. If the author of the name of a species proposed an epithet consisting of two or more words, but without hyphenating or joining, the form is to be corrected, but without prejudice.

NOTE 3. The elements of a compound specific epithet should be separated by hyphens if separately declined. If not separately declined they should be united.

Rule 7. The name of a subspecies (variety) is a ternary combination consisting of the name of the genus followed by a specific and a subspecific epithet in order.

An epithet of a subspecies (variety) is formed like that of a species; when adjectival in form and not used as a substantive it agrees in gender with the generic name.

Neither within the same species nor within the same genus may two subspecies bear the same subspecific epithet.

If the species is divided into subspecies, the subspecific epithet of the subspecies containing the type of the species must be the same as that of the species.

Minute 31. Emendation of Rule 5 (page 26 of the Code). The Commission approved the emendation of Rules $5 \mathrm{a}, 5 \mathrm{~b}$ and $5 \mathrm{c}$ by the addition of $5 \mathrm{~d}$ as follows:

Rule 5d. When a genus is so subdivided as to include sections, subsections, series and subseries, the names of these taxa are formed as follows:

(1) The name of a section is preferably either a descriptive adjective in the plural number agreeing in gender with that of the name of the genus or the plural of the specific epithet of the name of one of the speciesincluded in the taxon.

(2) The name of a subsection, series or subseries is preferably the plural of the specific epithet of one of the species included in the taxon.

(3) Within the same genus, no two sections, subsections, series or subseries may bear the same name.

NOTE 1 . The names given to sections, subsections, series and subseries do not compete with names of genera and subgenera as to priority or homonymy. 


\section{BACTERIOLOGICAL NOMENCLATURE AND TAXONOMY}

NOTE2. The names of subdivisions in the form of plural adjectives are treated as plural nouns. They resemble in this respect the names of suprageneric taxa which are in the form of plural adjectives but are also regarded as plural nouns.

Minute 32. Emendation of Recommendation 6b(7) (page 40 of Code). The Commission approved the emendation of Recommendation $6 \mathrm{~b}(7)$ to read as follows:

(7) To avoid compound specific epithets which include word stems from two or more languages (epitheta hybrida). This does not apply to hyphenated specific epithets in which the components are separately declined.

Minute 33. Emendation of Rule 8 (page 45 of Code).

A tentative proposal for emendation of Rule 8 relating to infrasubspecific forms was presented. There was general approval of the purpose of the proposal, but not sufficient time for adequate discussion. The permanent secretaries and chairman will seek through correspondence with the commissioners to draft a satisfactory statement. When drafted, it will be voted on by letter ballot.

The following is the draft presented to the Commission for consideration and revision: (The phrase "from Bradley draft" indicates paraphrases of statements made by Dr. Bradley in his draft proposals for the recent international Code of Zoological Nomenclature.)

\section{Draft Proposal for Emendation of Rule 8. Names of infrasubspecific subdivisions and infrasubspecific forms}

Definitions. An infrasubspecific subdivision is a taxon having a lower rank than a species (or subspecies).

An infrasubspecific form is one of the coordinate designations within an infrasubspecific taxon.

The names (terms) used to designate infrasubspecific subdivisions generally recognized are: strain, forma specialis, biotype, serotype, morphotype, phagotype, lysotype, phase, group. Less commonly used are the names (terms) state, stage, chemovar, chemotype. 
Page 6

\author{
INTERNATIONAL B U LLETIN
}

An infrasubspecific form within a species is designated by the name of the species followed by the term used to designate the infrasubspecific subdivisions (as serotype, strain), this in turn by the infrasubspecific designation, or epithet. This may be a Latin or latinized word, a vernacular name or word, a number, a letter, or a formula intended to characterize the organism.

The complete citation of the name of an inf rasubspecific form includes the binary combination of the species name followed by the term designating the infrasubspecific subdivision, this in turn by the epithet (or epithet substitute) of the infrasubspecific form and this by the name of the author.

A Latin or latinized infrasubspecific name may be elevated by a subsequent reviser to the status of a subspecific or species name. If so elevated, it ranks in its new status for purposes of priority from the date of its elevation and is to be attributed to the author by whom it was so elevated. (From Bradley draft)

Type strains (cultures of significant infrasubspecific forms) may be designated. The designations or epithets used in naming infrasubspecific forms are coordinate within each subdivision but not with the names of species or subspecies. (From Bradley draft)

Names of species and subspecies on the one hand and names of infrasubspecific forms on the other constitute mutually independent sections of nomenclature with respect to priority and homonymy. (From Bradley draft)

The Judicial Commission agreed that the Editorial Board should further consider the revision of Rule 8 and its Recommendations. The permanent secretaries were also requested to refer the question of the preferred use of the terms "lysotype" and "phagotype" to the two International Bacteriophage Subcommittees through their secretaries for consideration and recommendation.

Minute 34. Emendation of Recommendation 8a (pages 48-51 of Code). The Commission approved the following emendation and arrangement of Recomrnendation $8 \mathrm{a}$ :

Recommendation 8a (Revised). Authors of names of infrasubspecific subdivisions of species of bacteria should attend to the following recommendations and definitions: 


\section{BACTERIOLOGICAL NOMENCLA TURE AND TAXONOMY}

(1) A strain is made up of the descendants of a single isolation in pure culture. It may be designated in any manner, as by the name of the individual responsible for its isolation (as Corynebacterium diphtheriae strain ParkWilliams), by the name of a locality, by a number, or by some similar laboratory distinguishing mark. "Strain" may also be used to designate cultures of bacteria which correspond to cultivated "varieties" (cultivars) of higher plants in having some special economic significance.

(2) A special form (forma specialis) is an infrasubspecific form included in an infrasubspecific subdivision of a species of a parasitic or symbiotic microorganism distinguished primarily by adaptation to a particular host. It is named preferably by use of the scientific name of the host written in the genitive.

(3) Type is a term which has frequently been used incorrectly to designate a subdivision of a species, particularly in cases where the distinguishing characters are regarded as insufficient to justify the recognition of a subspecies. The term type in bacteriology (as throughout biology) should be used strictly in the sense defined in Principle 11 and Rule 9. It should not be used to designate infraspecific forms based on antigenic characters.

It is recommended that wherever appropriate the following terms be used to designate infrasubspecific subdivisions of a species: strain, forma specialis, biotype, serotype, morphotype, lysotype (phagotype), phase, group. Less commonly used are the names (terms) state, stage, chemovar and chemotype.

It is recommended that the term serotype (or serological type) be used for infrasubspecific forms based on antigenic characters.

It is recommended that the term biotype (or physiological type) be used for infrasubspecific forms based on differences in physiological characteristics.

It is recommended that morphotype (or morphological type) be used for infrasubspecific forms based on noteworthy differences in morphological characteristics.

It is recommended that lysotype (phagotype or phage type) be used for infrasubspecific forms based on relationships to bacteriophages. 
Page 8

INTERNATIONAL B ULLETIN

(4) The designation "phase". should be restricted to welldefined stages of a naturally occurring a lternating variation.

(5) The term "group" in bacteriology should be used with great careand be well defined if ambiguity is to be avoided. It has been used in somewhat different senses by those working in various fields of bacteriology. "Group" may appropriately be used to designate congeries of organisms having common characteristics. In many cases the groups are based upon antigenic analyses, they are assemblages of related serotypes. The term "group" has in some cases been employed to avoid the use of the correct nomenclatural name of a taxon such as genus or species. This use leads to confusion and should be avoided.

(6) State (or stage) is the name given to the rough, smooth, mucoid and similar variants which arise in cultures of many species of bacteria. These are usually regarded as alternating states which are often reversible, and indeed by some authors considered as part of a pleomorphic life cycle. They may be designated by some vernacular descriptive name.

(7) The term "chemovar (chemotype)" may be used to designate an infrasubspecific subdivision to include infrasubspecific forms or strains characterized by the production of some chemical not normally produced by the type strain of the species.

Minute 35. Emendation of Rules 9c and 9d (pages 54-56 of Code). The Commission approved the emendation of Rules $9 \mathrm{c}$ and $9 \mathrm{~d}$ as follows:

Rule 9c. Designation of the nomenclatural type of a genus or of a subgenus or of an infrasubgeneric taxon of the rank of section, subsection, series or subseries.

No changes in $9 c(1), 9 c(2)$ or $9 c(3)$.

Rule 9c(4). The nomenclatural type of a section, subsection, series or subseries shall be a species and its selection shall be governed by the rules governing the 
selection of type species for genera and subgenera as outlined in Rule 9c(1), (2) and (3).

Rule 9d. The nomenclatural type of a species or subspecies. The nomenclatural type of a species or subspecies may be a living culture maintained in a bacteriological laboratory, more particularly in one of the international or national type culture collections.

NOTEL. For a species which cannot be maintained in laboratory cultures or for which neither type cultures nor neotype cultures exist, the type is the original description, preparation or illustration.

NOTE 2.Definitions.

(a) The term culture is to be interpreted as including every method of maintaining organisms in a living state (in a medium, in a host by passage, in cells or exudates, frozen or desiccated).

(b) A type culture is a living culture of an organism which is a descendant of the original culture or an isolation from which the author who first described the organism made his original description, which culture has been maintained pure, and which agrees in its characters with the original description.

Minute 36. (See also Minute 65). Emendation of Rule 11 (page 61 of Code). A request for an Opinion concerning the validity of publication of names of taxa published in patents or in patent publications was received. The Commission concluded that an Opinion should not be formulated but that Rule 11 should be emended. For convenience in reference, the Minute 65 is therefore included also as Minute 36 under "Code Emendations."

$\mathrm{Dr}$. Cowan moved that the publication of the name of a bacterial taxon in a patent publication does not constitute effective publication. The motion was seconded and carried. Rule 11 was emended to read as follows:

Rule 11. Publication is effected under this Code by sale or distribution of printed matter to the general public or to bacteriological institutions. No other kind of publication is accepted as effective (effective publication). Communication of new names at a public meeting or scientific conference does not constitute effective publication. The 
inclusion of a name or description or both in a patent application or in a patent does not constitute effective publication.

Minute 37. Emendation of Rule $12 \mathrm{f}$ (page 67 of Code). The Commission approved the emendation of Rule $12 \mathrm{f}$ to read as follows:

Rule $12 \mathrm{f}$. The date of a name or of an epithet is that of its valid publication. For purposes of priority, however, only legitimate names and epithets published in legitimate combinations are taken into consideration. In the absence of proof to the contrary, the date given to the work containing the name or epithet must be regarded as correct. NOTE. The phrase "epithets published in legitimate combinations" is to be interpreted under the provisions of Rule 25 .

Minute 38. Emendation of Rule 13 (page 70 of Code). The Commission approved the emendation of Rule 13 to read as follows:

Rule 13. The name of a genus or subgenus is not validly published:

(a) Unless it is accompanied (1) by a description of the genus or subgenus; or by a citation of a previously and effectively published description of the genus as a subgenus (or subgenus as a genus); or in the case of a monotypic new genus based on a new species, by a combined generic and specific description; and (2) by description of one or more species, or by citation of a previously and effectively published description of one or more species included in the genus.

(b) If the description of the genus was based upon studies of impure or mixed cultures, that is, if there is evidence that the description was based on the properties of more than one species grown in a mixed culture. This statement does not apply to the name of a genus or subgenus whose description is based upon morphology or other characters and not upon growth in pure culture.

NOTE. A description of a new species assigned to a 
monotypic new genus is treatedalso as a generic description if the genus is not described. Similarly a description of a monotypic new genus based on a new species is treated also as a specific description if the generic name and specific epithet are published togethe $r$ and the species is not separately described.

Minute 39. Emendation of Rule 15a (page 73 of Code). The Commission considered the problem of citation of the authority for the name of a taxon when two or more authors are cited. In some recent cases as many as 8 or 10 co-authors are cited. The Commission instructed the Editorial Board to include a note to Rule $15 \mathrm{a}$ to indicate that where more than two names are designated as coauthors, it is appropriate to cite the name of the first author followed by "et al." (et alii). Further, a Recommendation should be drafted suggesting that, where a publication has several authors, wherever practicable one of these be definitely designated as the authority for the name. The following note was approved for addition to Rule 15a:

NOTE. When a publication includes more than two coauthors, citation of authorship of names of taxa included may appropriately be cited by use of the name of the first author followed by "et al." (et alii).

The following recommendation was also approved:

Recommendation $15 \mathrm{c}$. When a publication having several authors contains names of taxa for which authority should be cited, it is urged that one of the authors should be definitely designated for citation as author.

Minute 40. Emendation of Rule 21 (page 85 of Code). The Judicial Commission approved the emended Rule 21 with instructions to the Editorial Board that a NOTE should be appended specifically authorizing the Judicial Commission to make exceptions to the rule when there are well established subspecific name s contrary to the rule. In the discussion it was pointed out that the name Mycobacterium tuberculosis subsp. (var.) hominis is quite firmly fixed in the literature, and might be conserved. The emended 
Page 12

INTERNATIONAL B ULLETIN

Rule 21 reads as follows:

Rule 21. When several species are united as subspecies (varieties) under one specific name, or when a species is divided into subspecies, the subspecies which includes the type of the species used must be designated by the same epithet as that of the species.

NOTE 1 . The proposal of a subspecific name excluding the type of the species automatically creates another subspecific name which includes the type. The author of the species name is to be cited as the author of such automatically recognized subspecific name.

NOTE 2. The Judicial Commission has authority to make an exception to the rule where there is a well-established subspecific name not in accordance with the rule.

Minute 41. Emendation of Rule 25 (page 95 of Code). Section e of Rule 25 requires that the name of a species is illegitimate if it is published in a work in which the Linnaean system of nomenclature for species was not consistently employed. It was agreed that the statement was not clear, and that strict application would lead to rejection of many commonly accepted species names, leading to needless confusion. Rule 25 was emended to read:

Rule 25. A specific or subspecific epithet is illegitimate in the following special cases and must be rejected:

a. When such epithet is merely a word not intended as a specific epithet.

$\mathrm{b}$. When such epithet is merely an ordinal adjective used for enumeration.

c. When such epithet exactly repeats the generic name (tautonym).

d. When such epithet is a later homonym within the same genus, that is, when it duplicates a specific epithet previously and validly published for a species of the same genus based upon a different type.

NOTE. A specific epithet is not rendered illegitimate by publication in a species name in which the generic name is illegitimate. 
Minute 42. Emendation of Rule 26 (page 97 of Code). The Commission agreed that emendation of the Note to Rule 26 required some revision to supplement the addition of the Note to Rule 25. The following emendation of the Note to Rule 26 was approved:

NOTE. Where a new epithet is required an author may, if he wishes, adopt an illegitimate epithet previously given to the taxon (in an illegitimate combination) if there is no obstacle to its employment in the new position or sense; the resultant combination is treated as a new name and ascribed to its author.

Minute 42. Emendations of Recommendations 27a, 27c, 27f, $27 \mathrm{~g}$ and $27 \mathrm{~h}$ (pages 107,113 and 114 of Code). The Commission approved the emendations of Recommendations $27 \mathrm{a}, 27 \mathrm{c}, 27 \mathrm{f}, 27 \mathrm{~g}$ and $27 \mathrm{~h}$ to read as follows:

Recommendation 27a. When a name or epithet for use in bacteriological nomenclature is derived from a Greek word, the transliteration to Latin form (its latinization) should conform to classic usage. Appendix A (q.. .) to this Code may be used as a guide. If a later author corrects in a valid publication the spelling of a name or epithet incorrectly transliterated from the Greek, the correctly spelled word may be regarded as an orthographic variant of the name or epithet.

Recommendation 27c. For scientific names of taxa it is advisable to use another font from that used for the remainder of the text, or to space the letters, or to use some similar device appropriate to the text. Typescript scientific names should be underlined, to indicate that when printed they should appear in a different font, preferably italics.

Recommendation $27 \mathrm{f}$. The provisions of Recommendation $27 \mathrm{e}$ apply to an epithet formed from the name of a woman. When the epithet has a substantival form it is given a feminine ending.

Recommendation $27 \mathrm{~g}$. A new specific or subspecific epithet should be written in conformity with the original spelling of the word from which it is derived and in strict 
Page 14

INTERNATIONAL BULLETIN

accordance with the rules of Latin and Latinization.

Recommendation 27h. A specific epithet, even one derived from the nameof a person, should notbe capitalized.

Minute 44. Emendation of Provision 2, concerning "Lists of nomina conservanda" (page 123 of Code). The Commission approved the emendation of Provision 2 concer ning "Lists of nomina conservanda" to read as follows:

Provision 2. The avoid disadvantageous changes in the nomenclature of taxa by the strict application of the rules of nomenclature, the Rules provide for a list of names which must be retained as exceptions (nomina conservanda).

Minute 45. Emendation of Provision 4, paragraph 1, under "Permanent International Committee on Bacteriological Nomenclature" (page 124 of Code). The Judicial Commission approved the following emendations:

A Permanent International Committee on Bacteriological Nomenclature has been established by the International Association of Microbiological Societies in Congress. This Committee is so constituted that wherever practicable each country is represented by at least one member and no country by more than five. Nominations for membership are made preferably in each nation by the microbiological society which is the National Member for the International Association of Microbiological Societies (IAMS). The National Member is defined in Article 3 of the statutes of the IAMS, 1962. Nominations should be made in writing to one of the Permanent Secretaries of the Committee. Acceptance will be indicated by the Secretary and the nominees given temporary membership in the Committee pending action of the Committee and of the next International Congress, when election will be confirmed. If suitable national or regional microbiological societies or organizations do not exist, a primary nomination for a country not represented may be made by one of the Permanent Secretaries. When elected, such members shall serve until nominations are made by a national or regional microbiological society. 
Membership on the International Committee is of indefinite tenure; it may be terminated by resignation, death, request of the nominating organization, or by continued failure to participate in the work of the Committee.

Minute 46. Emendation of Provision 4, paragraph 3, under "Permanent International Committee on Bacteriological Nomenclature" (page 125 of Code). The Commission approved the following emendation.

Before each Congress, each national society shall inform the Permanent Secretaries of any recommendations relative to changes in its representation.

Minute 47. Emendation of Provision 4 under "Recognition of Alternates (page 125 of Code). The Commission approved the insertion of a fourth section after (a), (b) and (c), to be designated section (d) and to read as follows:

(d) An alternate need not be chosen from the society or country represented by the member.

The Commission agreed further to delete the paragraph which reads:

All nominations for alternates by national societies, or by members shall be in writing and should be in the hands of one of the Permanent Secretaries before the first meeting of the Committee.

Minute 48. Emendation of Provision 4 under "Functions of the International Committee" (pages 125 and 126 of Code). The Commission approved the expansion and emendation of Provision 4 under "Functions of the International Committee" to read as follows:

The International Committee on Bacteriological Nomenclature has the following functions:

(1) To hold meetings at the time of and as a part of the sessions of each Congress of the International Association of Microbiological Societies. 
(2) To consider and pass upon all recommendations made by the Judicial Commission relative to the formulation, the modification or the emendation of the International Code of Nomenclature of Bacteria and Viruses, or relating to the nomenclature of other groups of microbiological concern. In cases for which the approval of the International Microbiological Congress is also necessary the Committee will make the appropriate recommendations. Proposals for amendment to the Bacteriological Code shall be submitted to one of the Permanent Secretaries in sufficient time to allow publication in the International Bulletin of Bacteriological Nomenclature and Taxonomy at least 3 months before the next following International Microbiological Congress.

(3) To receive all Opinions issued by the Judicial Commission. Each Opinion of the Judicial Commission is final unless there has been filed a formal objection in which case the International Committee shall determine acceptance, rejection or othe $r$ appropriate action. Action by the International Committee shall be taken at the meeting of the Committee next following the date on which the Opinion was published or submitted to the Committee. Alternatively a decision may be made by the International Committee by letter ballot.

(4) To authorize, appoint and outline the functions of special subcommittees of experts to consider and make recommendations concerning the nomenclature of $\mathrm{mi}-$ croorganisms and to report on other phases of their taxonomy.

(5) To sponsor a Section on Taxonomy and to organize one or more sessions of such section at each International Congress, at which sessions there will be opportunity for presentation and discussion of reports of the several subcommittees on taxonomy.

(6) To receive and recommend to the Judicial Commission for publication the reports of the several subcommittees on taxonomy and to refer to the Judicial Commission any special problems that have been raised or recommendations that have been made respecting nomenclature. 
B ACTERIOLOGICAL NOMENCLATURE AND TAXONOMY

(7) To elect from the membership of the Committee the members of the Judicial Commission as vacancies may occur and to replace the members of the several classes as their terms expire.

(8) To appoint as Life Members of the International Committee on Bacteriological Nomenclature individuals who have rendered distinguished service to bacteriological nomenclature and taxonomy. Such Life Members shall be regarded as members-at-large and not as representing the microbiologists of any nation.

Minute 49. Emendation of Provision 4 under "Election of Chairman and Vice-Chairman (page 126 of Code). The Commission approved the emendation of Sections $A(2)$, $B(2)$ and $B(3)$ to read as follows:

A(2) To collaborate with the Chairman of the Judicial Commission, with the Permanent Secretaries and with the Vice-Chairman in the preparation of the Agenda for the meetings of the Judicial Commission.

B(2) To collaborate with the Chairman of the Committee, the Chairman of the Judicial Commission and the two Permanent Secretaries in the preparation of the Agenda for the meetings of the International Committee.

$B(3)$ To assume such other duties as may be requested by the Committee.

Minute 50. Emendation of Provision 4 under "Election of Two Permanent Secretaries" (page 127 of Code). The Commission approved the emendation of the last sentence of the first paragraph on page 127 of the Code to read as follows:

The Permanent Secretaries are voting members-at-large and shall not be included in the quota of any nation.

Minute 50a. Substitution of "General Meeting" for "Plenary Session" where appropriate in the Code. The Commission approved the change in wording where applicable in the 
Code to conform to the terminology in the 1962 statutes of the International Association of Microbiological Societies (IAMS).

Minute 51. Emendation of Provision 4 (1), (4), (7) and (8) under "The Duties of the Permanent Secretaries" (pages 127 and 128 of Code). The Commission approved the emendation of paragraphs $(1),(4),(7)$ and (8) as follows:

(1) To prepare, in cooperation with the Chairman of the Committee, the Vice-Chairman of the Committee and the Chairman of the Judicial Commission the Agenda for all meetings of the Committee and of the Judicial Commission.

(4) To transmit to the Committee from the Judicial Commission such recommendations as may require action by the Committee; in the intervals between International Congresses to duplicate and send such recommendations to all members of the Committee. If the members of the Committee are circularized to secure comments and suggestions, to tabulate the information received. If the members are asked to vote upon any proposal, to tabulate and announce the result of the ballot and to certify the results to the Chairman of the Committee and the Chairman of the Judicial Commission.

(7) To present all actions of the Judicial Commission or the International Committee requiring approval of said session, including the list of the names of members, with addresses, of the International Committee on Bacteriological Nomenclature, to the General Meeting of the Congress.

(8) One or the other of the Permanent Secretaries shall be a member of each subcommittee on taxonomy authorized or appointed by the International Committee for the purpose of maintaining liaison between the subcommittee, the International Committee on Bacteriological Nomenclature and the Judicial Commission. He shall receive from the secretary of the Subcommittee and transmit to the International Committee and to the Judicial Commission the reports and recommendations of the Subcommittee. When requested, he shall advise the Subcommittee on the interpretation 


\section{B ACTERIOLOGICAL NOMENCLATURE} AND TAXONOMY

of the International Code of Nomenclature of Bacteria and Viruses.

Minute 53. Emendation of Provision 4 (1), (3), (4), (5), (6), (7), (8) and (9) under "Functions of Taxonomic Subcommittees" (pages 128 and 129 of Code). The Commission approved the following emendations of Provision 4:

(1) The Chairman and Secretary of each Subcommittee on Taxonomy shall be elected by the members of the Subcommittees and shall hold office through two consecutive International Microbiological Congresses. They shall be eligible for re-election.

(3) One or the other of the Permanent Secretaries shall be designated as a nonvoting membe $r$ of each subcommittee and shall act as liaison between the subcommittee, the International Committee and the Judicial Commission.

(4) Each taxonomic subcommittee shall meet at each International Microbiological Congress and shall regularly review and revise its membership. The names of members who have retired or have ceased to interest themselves in the work of the taxonomic subcommittee, or who have died, shall be deleted from the membership list. The taxonomic subcommittee shall, if it desires, replace the inactive members by more active experts, but it is not essential to maintain the membership at a definite number. The list of members as revised shall be submitted to the liaison secretary for publication in the International Bulletin immediately following each Congress.

(5) The Chairman and Secretary of each subcommittee will be jointly responsible for the presentation of a report through the liaison Permanent Secretary to the International Committee. This report, if accepted by the International Committee, will be published in the International Bulletin of Bacteriological Nomenclature and Taxonomy. The report should include a review of work during the period following the meeting of the preceding International Congress and include a resumé of the minutes of the meeting held during the current International Congress. 
The Commission agreed to replace the present text with the following new statement (page 129 of Code):

(6) The primary functions of a subcommittee on taxonomy of a taxonare two: 1) to undertake and encourage research on the relationships of the organisms of the several units and subdivisions of the taxon under study, developing thereby better classifications from the practical standpoint of identification but without ignoring the significance of contributions to a better understanding of phylogeny, and 2) to advise and make recommendations relative to nomenclature. The subcommittees are encouraged to use any and all of the techniques of the several branches of science in recognition of characters useful in distinguishing microorganisms studied. The appropriateness of modification of rules and recommendations of the Bacteriological Code should be noted and proposals for emendation believed desirable made to the Judicial Commission. ${ }^{1}$ The preparation of exhaustive monographs of taxonomic groups is desirable. Particularly significant is recognition of type species of genera, and of type strains (cultures) and neotypes of species and subspecific taxa. Likewise important is the formulation of better nomenclatural treatment and taxonomy of the infrasubspecific forms.

The present No. (6) was given a new number (7) (page 129 of Code) and was emended to read as follows:

(7) A subcommittee may create one or more subgroups to study particular problems. Each subgroup shall have a chairman appointed by the subcommittee. The members of each subgroup shall be appointed by the subcommittee, but need not themselves be members of the subcommittee.

(8) When votes are celled for in subcommittees or subgroups, a simple majority shall suffice; in the event of a tie, the chairman shall have a casting vote. If members wish to record a unanimous decision, a fresh vote may be

1 While a stabilized classification cannot be legislated or created by fiat, in most areas a reasonably satisfactory stabilized taxonomy may be developed through consensus. 
called for. Votes shall be recorded by a show of hands unless a secret ballot is demanded by at least one-fourth of the members present.

The Commission agreed to retain unchanged the present sections numbered (8) and (9), but to renumber them as (9) and (10), respectively.

Minute 53. Emendations of Appendix B (pages 143 and 144 of Code). The Commission approved the emendation of the introductory paragraph to read as follows:

Alternative spellings (orthographic variants) of names or epithets found in the literature of microbiology frequently have resulted from alternative or faulty spelling of Latin words, from faulty or alternative transliterations of Greek words into Latin form, from faulty or alternative endings used to indicate gender or case when Greek words are transliterated, from alternative vernacular endings of names of suprageneric taxa, from use of an ending (suffix) prescribed in Rule 4 for the name of a suprageneric taxon of one rank instead of the appropriate (prescribed) ending (suffix) of the name of a suprageneric taxon of another rank, and from use of endings (suffixes) prescribed in the Zoological Code for names of suprageneric taxa. Authors of new names of taxa and of epithets are urged to make choices in conformity with the following recommendations:

The Commission further approved the addition of a section (d) following (c) on page 144 of the Code:

(d) Alternative spellings of endings (suffixes in names of suprageneric taxa.

1. Names of suprageneric taxa betweengenus and subclass which include the stem of the name of the type genus and which have been published with a vernacular ending (suffix) may be corrected without prejudice to the first author and date of publication. Example: Bacillacéi Fischer 1895, was corrected to Bacillaceae Fischer 1895 by Lehmann and Neumann 1896.

2. Names of suprageneric taxa between genus and subclass designated by an author as having a given rank 
but with a suffix (ending)appropriate only in another rank may be corrected without prejudice to the first author and date of publication.

Example: The name Amoebobacteriaceae Migula 1900, 1095 was designated as a subfamily. It may be corrected.

3. Names of suprageneric bacteria taxa between genus and subclass in which the ending (suffix) is that of a rank recognized in the Zoological Code may be corrected without prejudice to the first author and date. Example: The name Schaudinnidae Enderlein 1917, was proposed for a family. It may be corrected.

\section{NOTES.}

1. No other biological code of nomenclature clearly outlines procedures to determine validity of publication or legitimacy of the three kinds of cases listed. There are many of these problems in bacteriology.

2. Names of suprageneric taxa between genus and subclass under the rule of the Bacteriological Code are formed by adding the appropriate taxon ending (suffix) to the stem of the type genus. The endings prescribed (Rule 4) are as follows:

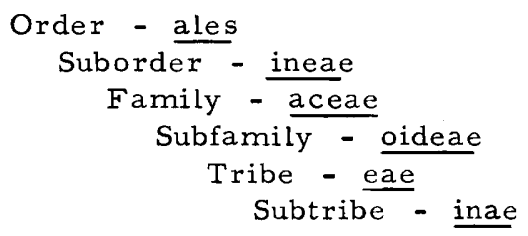

